I would advise you to look at carefully. It is, shortly, as follows:-Robert $\mathrm{S}-$, aged twenty-one, a clerk, until fourteen years of age healthy; since fourteen he has been gradually reaching his present niserable state, which may be thus described :- He cannot stand steadily, and walks in a trembling, tottering manner ; his unsteadiness is but little increased when he shuts his eyes; movements cease when he lies down and the limbs are supported; his face lacks expression, and his attempts to speak usually cause some quivering of the lips; his words are slurred, syllables run into each other, much as if he were slightly intoxicated; his tongue, when protruded, is steady, except for fibrillar quivering. Thus, his state would correspond with the description of general paralysis of the insane, but it nevertheless is not at all of that kind. It has lasted too long. The mental faculties are very fair. But if you want proof how far remote it is from general paralysis, you must hear his curious family history. $\mathrm{He}$ is one of seven children of a respectable tradesman. There was no eonsanouinity of parents ; there is no sign of hereditary syphilis. The parents were fairly well off. Three of the children have grown up and continued healthy people, but it is otherwise with four of them, of which four he is one, and the other three of this four are all afflicted in the same way as he is. They differ from him only in the stage of the disorder. The eldest of them is a man thirty-six years old, the second a woman of twenty-six; the first of these has been twenty-two years, the second twelve years, in the disorder. These two can only get about with great difficulty, but their condition has not grown worse for some years. A brother younger than our patient-aged, I think, seventeen - is the fourth of these unfortunates. He is just beginning to be seriously troubled with the same set of symptoms, which must shortly make him, from what he appears-a tall, well-built, hearty ladinto a paralytic wretch like our patient. Having seen them all, I find the cases identical in all the points above-named, although the persons differ in complexion, stature, \&c., just as much as is usual in families. I do not know at all certainly what is the change that has overtaken the nervous centres in so many of this unhappy family at the same age in each. But, whatever it is, the condition of the sufferers is the same as that of the poor man of small property whom it was found most convenient to treat as a lunatic, and whose case I have just stated.

If time allowed, I could give you other cases of the same kind. They are, as you have seen, so like general paralysis of the insane as to run great risk of suffering injustice at the hands of the authorities. They are also very like insular or disseminated sclerosis ; I prefer the term "insular," because the word "disseminated" carries, to my mind, the idea of small scattered things, whereas the patches in selerosis are islet-like areas of often large size: you would hardly call half-crowns on the palm of your hand "disseminated." They are also like locomotor ataxia: the quasilunatic was described by the Commissioners as having locomotor ataxia. But they differ from general paralysis in the intelligence being retained; the muscular tremors or jactitations are more considerable, and the course of the case is quite different and much more protracted. They differ from insular sclerosis in there being much less mental enfeeblement than is met with in sclerosis; also in the muscular tremor being rather choreiform than oscillatory-choreiform, not choreic: it is known at once from chorea by the movements ceasing when the limbs are supported. From locomotor ataxia they are distinguished by the implication of the apparatus of speech, and by the absence of the pains and numbness of ataxia. Again, from all these they are distinguished by the circumstances and the course of the disorder. My object in this lecture is to direct your attention to such general paralytic enfeeblement closely resembling the diseases I have named in association with it, and having the characters described in the cases I have criven; and I bolieve you will find yourselves repeatedly meeting with this lisorder if you are ready to recognise it.

As to the treatment of this particular trpe of disease, I have seen no good whatever-that is, no specially curative rood-from any treatment. Like so many chronic nervous iliseases, they generally fall, at least for a good long timerood, that is, for the electrician-under some medical electrician, who may attract them by means of a continuous current of advertisements of his books and cases in the press and medical societies. The electrician's proceedings are impressive, and the noor creatures are always touchingly ready to suppose themselves to be improving; but no real gocd is ever done in any such case when once the case has becone so pronounced in character that its correspondence with the above type of disease is certain.

\section{INTRA-CAPSULAR FRACTURE OF THE NECK OF THE FEMUR, \\ WITH GREAT FLEXION, ADDUCTION, AND INVERSION OF THE LIMB.}

BY WILLTAM PIRRIE, M.D., LL.D. EDIN., SURGEON IN SCOTLAND TO H.R.H. THE PRINCE OF WALES, AND PROFESSOR OF SURGERY IN THE UNIVERSITY OF ABERDEEN.

WIDow M- a thin, pale, weakly-looking woman, eighty years of age, was admitted into one of my wards in the Aberdeen Royal Infirmary on Monday, the 14th of October last, having sustained a severe fall on the lower part of her back and right hip, caused by tripping on a doormat and falling upon a bare hard floor, the accident having happened two days previous to her entrance into the hospital.

The patient was admitted at the conclusion of the visit on Monday, and stated to me on Tuesday, that since the occurrence of the accident she had suffered intense pain in the region of the right hip, that the limb had remained immovable in the same position, and that her urine and freces had been passing off involuntarily.

Before bringing the patient under the influence of chloroform, with the view of making a thorough examination, I observed that she could only lie on her back inclined to the left side, with the right thigh so much flexed, adducted, and inverted, that her right knee lay high up in the left lumbar region, that the outer aspect of the thigh looked directly forwards, and that it was necessary to support the right foot by means of a pillow in order to prevent ite falling down and thus rotating the thigh outwards, which caused excruciating pain at the hip-joint. (A glance at Fig. 1 will

FIG. 1.

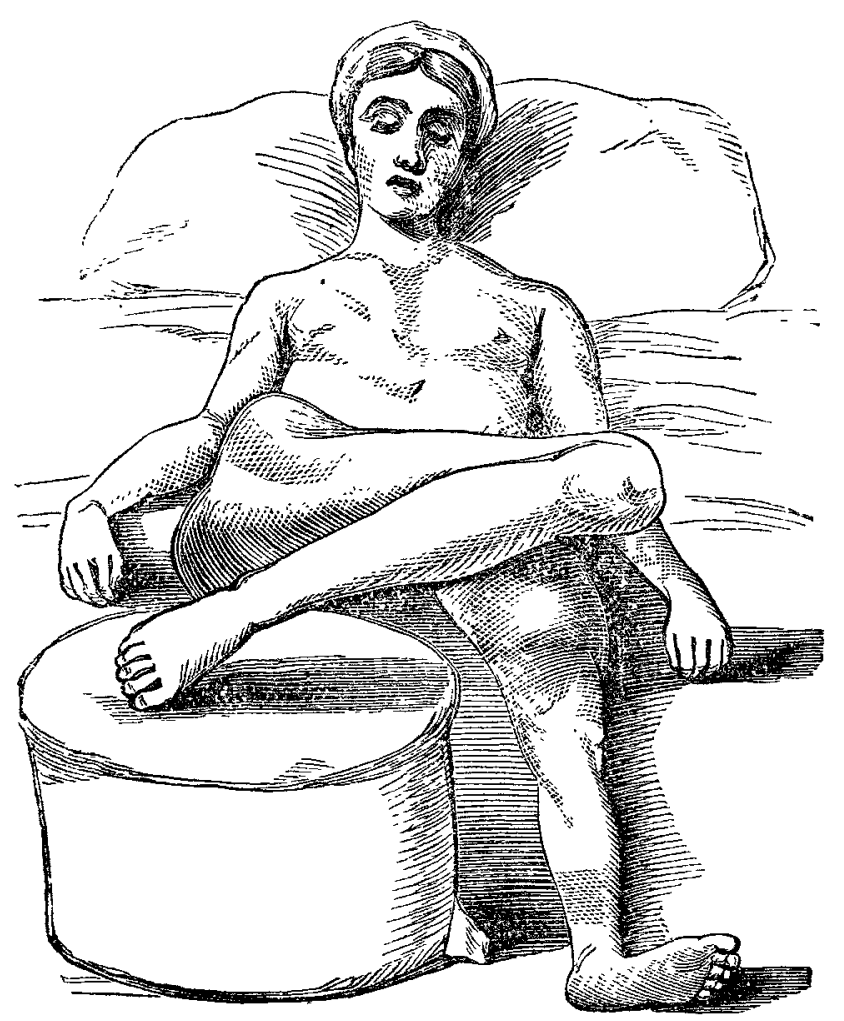

make the attitude of the limb interyibie.) From the lower part of her back and posterior asject of the right hip a portion of skin about the size of the hand had been removed by the fall, and a black, gangremons slougli had formed on the denaded part. When the cxanination had proceeded thus far, I thought that this case wis probably an examplo of that peculiar dislocation of the in -joint described by 
Bigelow, and delineated by Fig. 13, page 63, of his most interesting work on "Dislocations and Fractures of the Hip-joint," a copy of which figure is here inserted. The FIG. 2.

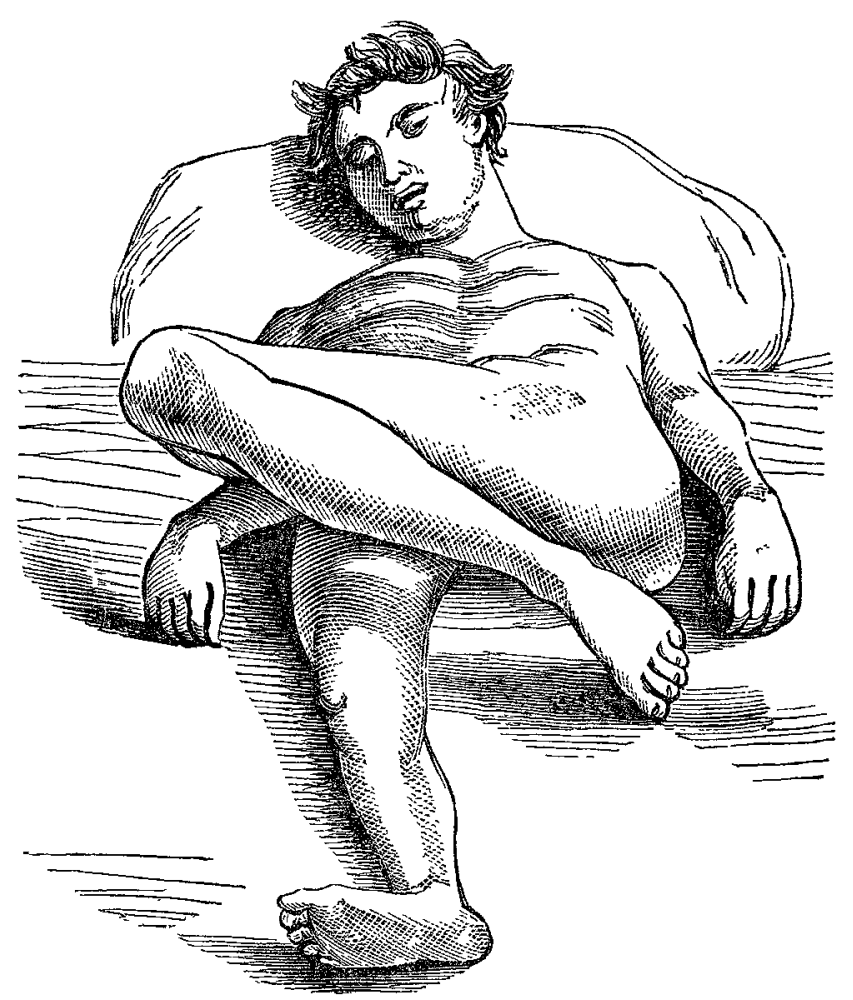

patient having been brought under the influence of chloroform, I easily traced with my finger the outline of the trochanter major, and found that its upper border was directed downwards and backwards. I could not discover the ball of the femur, and therefore came to the conclusion that it remained in the acetabulum. On rotation of the thigh, the trochanter major did not describe the segment of a circle, as in a dislocation, but was observed to revolve on its own axis, as in fracture of the neck of the thigh-bone, and during rotation slight erepitation was elicited. From the above symptoms, I was convinced that this was a case of fracture of the neck of the femur with flexion, adduction, and inversion of the limb, a variety of fracture not hitherto described, as far as my reading has enabled me to judge. Having formed this opinion, I reduced the fracture by taking hold of the knee with one hand and the foot with the other, by placing the leg at a right angle to the thigh, by abducting, rotating outwards, and bringing down the limb by the side of the other-in short, reduction was accomplished by practising the last three movements adopted by Bigelow for reduction of dislocation of the head of the femur on the dorsum of the ilium. When the limb was thus brought into proper position, it exhibited no tendency to eversion or inversion, and there was scarcely any appreciable shortening.

For the first twenty-four hours following reduction the affected extremity was kept at rest by placing a long sandbag by the side of the patient's trunk and limb, and afterwards by applying to the outer side of her pelvis, thigh, leg, and foot a long splint, composed of long broad bandages charged with plaster-of-Paris, and moulded into the shape of a Desault's splint. The test-line of the ilio-femoral triangle, shown by Bryant to be so valuable for enabling the suroeon to arrive without excessive manipulation at a reliable diagnosis in fractures of the neck of the thigh-bone and Nélaton's test-line for dislocation of the head of the femur backwards, were not available in this case, owing to the extraordinary pocition of the femur; but the already described symptoms produced a decided conviction in my mind that the case was one of fracture of the neck of the thigh-bone with the limb in a position which I had never before seen in any example of that injury, and the postmortem examination made six weeks after the reduction of the fracture proved that my diagnosis was correct.

From the moment that the limb was made straight the patient remained perfectly free from pain in the hip, but frequently complained of pain at the knee, which was perfectly sound. This pain was chiefly seated within and at the inner side of the joint-a symptom so common in morbus coxi, --sometimes misleading an unwary surgeon, but rarely, if ever, met with in injuries of the hip-joint, judging from my own experience. If the conditions in which this symptomatic pain is experienced be disease at the filamentous terminations of one branch of a nerve, and the pain reflected to the terminations of another branch of the same nerve, conditions furnished by the anterior branch of the obturator nerve supplying the hip, and the posterior branch the knee-joint, it is difficult to understand why the symptomatic pain is experienced so severely and frequently at the knee in disease, and so rarely, if ever, in painful accidents, of the hip-joint.

Six weeks after the application of the plaster-of-Paris bandage-splint, and three days before the death of the patient, the splint was removed, and the limb remained straight, without any tendency to eversion or inversion, and there was no appreciable shortening.

Notwithstanding the occasional and unavoidable contact of urine with the denuded surface on the patient's back, which was covered with a large gangrenous slough on her admission, by the application of turpentine, carbolic, and other dressings, and the removal of all pressure by means of a water-pillow ring filled with air, the slough eventually was removed, and granulations made some advancement; but these attempts at healing were fruitless, owing to the great weakness and age of the patient. The weakening effects of this large sore, together with amyloid degeneration of the kidney, caused death fifty days after the occurrence of the injury.

The post-mortem examination was conducted by $\mathrm{Dr}$. Rodger, pathologist to the Aberdeen Royal Infirmary, who found that the capsular and ilio-femoral ligaments were perfectly entire, the latter being thicker and stronger than usual, that the neck of the femur was fractured close to the ball of the bone, the plane of the fracture being at a right angle to the long axis of the neck; that the outer fragment was considerably shortened, débris occupying the plane of the fracture; that there were no bands uniting the fractured surfaces to one another, and that there was no effusion into the joint, and no signs of the inflammatory process. The round ligament was perfectly entire, showing that the ball of the bone had never left the cavity of the acetabulum.

I believe that the integrity and tension of the ilio-femoral ligament was the cause of the adduction, flexion, and inversion of the limb, and that by its causing the centre of motion to be situated at its attachments to the anterior inter-trochanteric line of the femur was the explanation of the facility with which the outer fragment was returned into its proper position by the manipulation of the limb.

Of the one hundred and thirty cases of intra-capsular fracture of the neck of the thigh-bone which have come under my notice, and where the accuracy of diagnosis was verified by dissection, this is the only case I know of with flexion, adduction, and rotation inwards of the limb. Of the remaining number, in one case only have I met with rotation inwards, the limb in other respects occupying the usual straight position. I watched that case of intra-capsular fracture with inversion during life, and had an opportunity of verifying the diagnosis after death, and have been for many years in the habit of exhibiting the preparation to the students of surgery in the University of Aberdeen.

\section{ON THE DANGER ATTENDING THE USE OF THE STOMACH-PUMP.}

BY SiR JAMES ALDERSON, M.D., F.R.S., PHYSICIAN EXTRAORDINARY TO THE QUEEN.

In tenui labor.-VIRG.

Though low the subject, it deserves our pains.-DRYDEN.

So great is the outcry by the public in cases of poisoning for the use of the stomach-pump that I shall be excused in pointing out the dangers of its employment, more especially in unskilful hands. The annexed drawing is from an illus. trated work on "Poisons," by the late Dr. Roupell and Mr. McWhinnie, showing the damage to the internal coat of the stomach by the exhausting power of the pump in a case of poisoning by arsenic. The case occurred soon after the introduction of the instrument into use.

In all cases of soluble poison the full effect of the stomach- 